\title{
Mothers' Attitudes and Self-Esteem among Deaf Children in Iranian High Schools
}

\author{
Effat Hamed Sardar (Corresponding author) \\ PhD Student, Faculty of Educational Studies, Universiti Putra Malaysia \\ 43400 UPM Serdang Selangor, Malaysia \\ Tel: 60-17-3182-8805 E-mail: afrooz.hamed@yahoo.com \\ Assoc Prof. Dr. Rusnani Abdul Kadir \\ Department of Counsellor Education and Counselling Psychology \\ Faculty of Educational Studies, Universiti Putra Malaysia \\ 43400 U.P.M. Serdang, Selangor DarulEhsan, Malaysia \\ Tel: 60-3-8946-8118Ｅ-mail: rak@educ.upm.edu.my
}

Received: July 28, 2011

Accepted: September 20, $2011 \quad$ Published: February 1, 2012

doi:10.5539/ass.v8n2p147

URL: http://dx.doi.org/10.5539/ass.v8n2p147

\begin{abstract}
This study examines the relationship between mothers' attitude and self-esteem among deaf children who are currently enrolled in deaf high schools in Iran. While family system theory is typically used in trying counseling and therapy, much can be learned from examining it by studying the relationship between deaf children and their mothers. Family systems theory has been used in trying to understand problems of communication between children and their families (Widerman, 1995). In general, attention with some significant findings has been focused on environmental factors such as parenting, communication at home, and type of schooling as potential contributors to self-esteem (Crocker, 2008). However, the role of other variables such as family's attitude has not been systematically explored. This implies that the picture is far from complete. It is also not clear what kind of factors effect on deaf children's self-esteem. Henceforth, the findings of this study may be helpful in the development of curriculum goals for increasing self-esteem in deaf children. Counselors and social workers can do much to promote positive family relationships as well as acceptance of disabilities in deaf children.

The sample consisted of 200 deaf children (100 boys and 100 girls) and 200 normal-hearing mothers. The study was conducted at deaf high schools in Iran. Rosenberg Self-Esteem scale, Parental Attitudes towards Deafness and interviews Scale were used. The results showed that a relationship existed between mothers' attitude and deaf children's self-esteem. Additionally, according to the Pearson correlation test, there is a relationship between the mothers' attitudes and self-esteem in deaf children. Children whose mothers ably communicated had higher self-esteem scores than their counterparts whose mothers could not ably communicate. The findings of this study may be helpful in the development of curriculum goals for increase of self-esteem in deaf children. Counselors can do much to promote positive family relationships as well as acceptance of disabilities in deaf children. Also, these findings may expand our understanding of the characteristics of deaf children's self-esteem and their families' attitudes. In terms of practical value, it is hoped that these findings provide information that may help determine efficacy of self-esteem, for deaf children and their families.
\end{abstract}

Keywords: Attitude, Deaf, Self-esteem

\section{Introduction}

Positive self-esteem plays an important role in one's successful performance. The deaf form a minor group in society and unfortunately people's judgments on this group accompany negative prejudges (Bat-Chava, 1993; Crowe, 2003). A study on deaf people's self-esteem revealed that there is a noticeable difference between their self-confidence and that of normal people (Bat-Chava, $1994 \&$ Schlesinger, 2000). The effects of deafness on one's social- emotional development are crucial. Those who lack self-esteem surely feel desperate and this may 
cause a negative attitude toward others. Deafness as a hidden disability cannot be observed as direct as other disabilities and since society to a great extend relies on language, it's no wonder that many researchers have concluded that those suffering from impaired hearing have characteristics differentiate them from hearing people (McGrath, 1993).

In studies, factor such as kind of education, parent's role, deaf parent's impact, the severity of deafness, age of onset, deaf child's communication at home and kind of hearing aid are taken into consideration (Crocker, 2008). The focus of most studies is on deaf parent's communication with their hearing children. Parent's attitude towards deafness and their deaf child, and its relation with self-esteem have received little attention. Self-esteem is an important concept in human psychology and individual behavior since it has been shown to have a pervasive and powerful impact on human cognition, motivation, emotion, and behavior. Previous studies have shown that it is highly correlated with the overall psychological well-being (Rosenberg, 1995), achievement, and the ability to cope with stressful life events (Campbell \&Lavallee, 1993).

The positive thinking and attitudes of the family are critical to the growth and development of their child's self-esteem. Families that approach deaf children's issues related to hearing loss in a positive way will then positively impact their children's self-esteem. The attitude of parents and siblings in accepting the disability influences the child in different ways. When negative attitudes are formed, they lead to hatred, hostility and injustice. This can be clearly shown when the parents unfairly blame or reject the child for something not due to his or her own doing. Deafness often instills a sense of mourning among parents (Meadow-Orlans, 1990). None the less, there are factors influencing their self-esteem positively or negatively. For instance, deaf children who communicate with their parents through sign language have higher self-esteem than those with parents insisting on the use of oral communication (Foster, 1998). Another study showed that the way family members communicate can determine deaf children's self-esteem (LaSasso\& Metzger, 1998). Therefore, it can be interpreted that when deaf children belong to a group, their self-esteem increases. It only refers the type of parent's communication in this study. Whereas correct communication with a deaf child can be effective in family relationship, its neglect causes low self-esteem.

Woolfe\& Smith (2006) studied whether or not hearing parents or siblings are important in deaf children's self-esteem. Forty five deaf children with deaf parents and siblings, deaf parents with hearing siblings, hearing parents with deaf siblings took part in this study. The result showed higher self-esteem for those with hearing parents but did not show any important correlation for sibling whether hearing or deaf. However, what was important was families' connection for all types. Deaf children with deaf parents and siblings feel more intimate than those with hearing families.Another research was conducted to study parent's attitude towards their deaf children. The subjects were parents (30 fathers, 30 mothers) with their twelve-year old deaf children living in Mumbai, India. Results showed that father's attitude was more positive in comparison to mothers (Kumar \&Rao, 2008).

According to Schilling \&DeJesus, 1993, the relationship between a deaf child and mother is influential on their relation. Further studies on mother-child relations in deaf children prove that early interference and teaching effective communication for improving positive views are influential in constructive relationships between deaf mothers and deaf children.Therefore, the in current study, the researchers senses that it is important to study the relationship between mothers and their deaf children's self-esteem. According to the family system, parents have a great role in forming and developing children's behavior and the environment where a child grows is a good feature of self-esteem. Concerning a deaf child, this is reception or rejection atmosphere, so it seems there are other variables affecting deaf children's self-esteem such as family attitude (Russell \& Miller, 2002).Finally, these problems can result in low self-esteem of children. According to Siavashi (2009), there must be a comprehensive plan for improving deaf children's self-esteem in Iran. Hence, in researchers' view to set a holistic program, variables likes parent's attitude especially mothers towards deafness. It is likely for these variables to have a deaf impact on the success of this program. Therefore, this study examines the relationship between Mothers' attitude and self-esteem among deaf children who are currently enrolled in deaf high schools in Iran.

\section{Instruments}

In this study, the Rosenberg self-esteem scale was used, because the scale is considered a standard in measuring self-esteem. As reported by Blascovich and Tomaka (1991), for hearing individuals, it has Cronbach alphas ranging on items from .77 to .88 and a previous study had a .63 Cronbach alpha for deaf individuals (Bat-Chava, 1994). In this study, the reliability index of Cronbach's alpha for overall self-esteem was .64. The scores were summed for a possible range of scores from 10 to 50. The questionnaire was translated into Persian sign 
language for deaf children. The respondents were deaf children who enrolled in high schools. The scale contained a 10-item scale. The original scale contained 10 items rated on a forced-choice scale from (1) Strongly disagree, (2) Disagree, (3) Agree, to (4) Strongly agree.

The attitude towards deafness scale was used to measure mothers' attitude towards deafness. The respondents were deaf children's mothers. The researchers measured mothers' attitude towards acceptance and rejection reality of deafness, attitude towards use of hearing-aid, use of sign language and mothers' attitude towards deaf learning process. The index reliability of Cronbach's coefficient alpha was then computed using the SPSS 16.0 for this instrument. A commonly agreed cut-off does not exist. Usually 0.7 and above is acceptable (Nunnally, 1978). However, Ary, (2002) pointed out that a lower reliability coefficient (in the range of 0.5 to 0.6) might be acceptable if the measurement results use in making a decision about a group or even for research purposes. In appendix E1 the statistical results of the reliability index of Cronbach's alpha for overall attitude was .71. Thus, based on Nunnally (1978) cut off point the reliability of this instrument is acceptable. The statistical results of the reliability indexes of Cronbach's alpha for attitude towards acceptance as first subscale of attitude was .72, for rejection reality of deafness was .74, for attitude towards use of hearing-aid was .74, for use of sign language was .73 and for finally mothers' attitude toward deaf learning process as last subscale was .64. Therefore, based on mentioned cut off point the overall attitude and its' subscales are in acceptance level of reliability. The sample consisted of 200 deaf adolescent students (100 females\& 100 males) and 200 (their) mothers. This group attended a southern residential school for deaf students. Additionally, the researcher conducted an in-depth interview .According to Sandall, (2002) qualitative research especially interview has the potential to increase our understanding of children with special needs, their families and those who work with them. Additionally, this type of research also has the potential to deepen our understanding of the intervention issues and challenges that children with special needs pose.

\section{Results}

Based on the table of coefficient, there is a statistically significant correlation between self-esteem and five components of mothers' attitude (Mothers' positive attitude towards deafness, mothers' negative attitudes towards deafness, mothers' attitudes towards hearing aid and mothers' attitudes towards deaf learning process). According to the results of this table, there is a significant negative and small correlation between mothers' attitude of deaf children and the children's self-esteem $(\mathrm{r}=-0.20, \mathrm{p}<0.05)$. In addition, a significant positive and small correlation was found between mothers' positive attitude towards deafness and deaf children's self-esteem $(\mathrm{r}=0.22, \mathrm{p}<0.05)$, a negative and small correlation was found between mothers' negative attitude towards deafness and deaf children's self-esteem $(r=-0.36, \mathrm{p}<0.05)$. However there is no significant correlation between self-esteem of deaf children and their mothers' attitude toward sign language $(r=-0.10, p>0.05)$. The results showed, there is significant negative and small correlation between self-esteem of deaf children and mothers' attitude towards hearing-aid $(\mathrm{r}=-0.20, \mathrm{p}<0.05)$ and in the end, a significant positive and small correlation was found between deaf children's self-esteem and their mothers' attitude towards deaf education $(r=0.21, \mathrm{p}<0.05)$. Thus, based on the reported results, the null hypothesis is rejected (Table 1).

\section{Discussion}

The findings of the study support the practice wisdom that a deaf children's self-esteem may be influenced by the parents' attitudes. Some researchers support this variable. Meadow-Orlands (1990) found that the positive thinking and attitudes of the family are critical to the growth and development of their child's self-esteem; families who approach deaf children's issues related to hearing loss in a positive way will then positively impact their children's self-esteem. The attitude of parents and siblings in accepting the disability influences the child in different ways. When negative attitudes are formed, they lead to hatred, hostility and injustice. This can be clearly shown when the parents unfairly blame or reject the child for something not due to his or her own doing. Deafness often instills a sense of mourning among parents.

However, in other studies, the relationship between the deaf child's self-esteem and their mothers' attitude about them has not yet been clearly discussed. What have been discussed were just overall positive and negative attitude about the issue. In this paper, however, five different categories were studied, namely, acceptance of deafness, rejection of deafness, mother's attitude towards use of hearing-aid, the mother's attitude about sign language and the mother's attitude about her deaf child's toward the deaf learning process. As Tombull (1990) believes, there are three main aspects that tell the person's inability can affect the system of the family. First, the disable person's peculiarity, second his/her family's characteristics and finally how they interact and communicate with one another. As Khadivizand (2008) believes, the distinction between these moods in different variants such as the deaf child's perception of his/her mother's treatment, his/her feelings and attitudes 
about him/herself and the mother's view about deafness would show their relationships. The interviewees' answers would support the results of quantitative findings (Table 2).

According to Schilling \&DeJesus, (1993), compromised communication between a deaf child and mother may affect their relationship and lead to parents becoming more protective. Hadadian (1995) believed that when the parents have a negative glance on their deaf child, the communication of the deaf person with other people would be decreased too and this will lead to a decrease in self-confidence and loneliness. The positive thinking and attitudes of the family are critical to the growth and development of their child's self-esteem; families who approach deaf children's issues related to hearing loss in a positive way will then positively impact their children's self-esteem. The attitude of parents and siblings in accepting the disability influences the child in different ways.

Therefore, the understanding of deaf children's self-esteem is important for family for it is the first step in developing self-esteem in deaf children. In addition, the professionals can help involve family through counseling and coaching about how to manage their deaf children. The social workers and counselors can help hearing parents navigate through their feelings and reactions by acknowledging the parents' feelings of disbelief, grief, guilt, and anger. Even if the hearing loss was diagnosed years ago, it may not be until the child enters school that the parents confront the previously denied feelings of loss and their fears about their child's education and psychosocial development. The counselors and social workers needs to gently explain the importance of recognizing the significance of the child's hearing loss and the importance of early and ongoing intervention. Then the social workers and counselors can educate the parents about the various aspects of their child's deafness and how their acceptance of their child affects his or her self-esteem. The social workers and counselors should impress on the parents to accept their child not as defective but as different.

\section{Limitations of the Study and Recommendations for Future Research}

The current research shows how a variety of quantitative statistical analysis can be used together with interview data to complement each other. The findings and conclusions drawn from this study are constrained by the characteristics of these specific passages used in the present research and may not be generalizable to other reading passages and contexts of study.The study focuses specifically on deaf children's self-esteem and mothers' attitude. Only high schools for the deaf in the Mashhad area are selected because the highest number of deaf children is found to be studying in Mashhad city. Although these groups of children fall under the umbrella of education of the deaf, they would likely use Persian sign language. Children with mothers or one parent deaf or deceased were excluded from the study. This is because one of the most important variables of this research is parental attitudes. According to Brown (2002) self-esteem is a multidimensional psychological construct which comprises affective disposition, affective states (feelings of self-worth) and affective value of different outcomes. In this study, only some factors in deaf children's self-esteem (for example self-acceptance, worthiness and feelings of confidence or global self-esteem) were measured by the researchers.

Mother's attitudes can include other components such as mothers' attitude towards the teachers of their deaf children. Hence, teacher education needs to include a focus on knowledge, skills and performance based on the application of what is learned and understood (knowledge), language acquisition principles, three levels of literacy and being involved in attitude planning for accessible educational environment such as skills, and having the language proficiency that affect deaf children's self-esteem. This is another aspect to consider for future study.

\section{References}

Ary, D. (2002). Introduction to research in education. USA: Wadsworth.

Bat-Chava, Y. (1994). Group identification and self-esteem of deaf adults. Personality and Social Psychology Bulletin, 20, 494-502. http://dx.doi.org/10.1177/0146167294205006

Bat-Chava, Y. (1993). Antecedents of self-esteem in deaf people: A meta-analytic review. Rehabilitation Psychology, 38, 221-234. http://dx.doi.org/10.1037/h0080303

Blascovich, J. \& Tomaka, J. (1991). The Self-Esteem Scale.In J.P. Robinson, P. R. Shaver, \& L. S. Wrightsman (Eds.). Measures of personality and social psychological attitudes, Vol. 1 (pp. 121-122). San Diego: Academic Press.

Campbell and Lavallee. (1993). J.D. Campbell and L.F. Lavallee, Who am I? The role of self-concept confusion in understanding the behavior of people with low self-esteem. In: R.F. Baumeister, (Editor). (1993), Self-esteem: The puzzle of low self-regard. Plenum, New York. 
Crocker, J. \& Luhtanen, R. K. (2008). Level of self-esteem and contingencies of self-worth.Unique effects on academic, social, and financial problems in college students. Personality and Social Psychology Bulletin, 29, 701-712. http://dx.doi.org/10.1177/0146167203029006003

Crowe, T. V. (2003). Self-esteem scores among deaf college students: An examination of gender and parents' hearing status and signing ability. Journal of Deaf Studies and Deaf Education, 8, 199-206. http://dx.doi.org/10.1093/deafed/eng003

Foster, S. B. (1998). Communication experiences of deaf people: An ethnographicaccount. In I. Parasnis (Ed.), Cultural and language diversity and the deaf experience (pp. 117-135). New York: Cambridge University Press.

Hadadian. (1995). An investigation of parent's attitude and the communication skills of their deaf children. American Annals of the Deaf, 136, 273-277.

Khadivizand, M. (2008). Creativity in Interviews. Journal of Psycho-Analysis, 19-26.

Kumar \& Rao. (2008). Parental Attitudes towards children with hearing impairment. Asia Pacific Disability Rehabilitation, Vol. 19 (2).

LaSasso, C. J. \& Metzger, M. A. (1998). An alternate route for preparing deaf children for BiBi programs: The home language as L1 and cued speech for conveying traditionally spoken languages. Journal of Deaf Studies and Deaf Education, 3(4), 265-289.

McGrath, M. \& Grant, G. (1993). The Life-cycle and Support Networks of Families with a Person with a Learning Difficulty. Disability, Handicap and Society, 8, 25-42. http://dx.doi.org/10.1080/02674649366780021

Meadow-Orlans, K. P. (1990). The impact of a child's hearing loss on the family. In D. F.Meadow-Orlans, K.P.Steinberg, A.G. (1993). Effects of infant hearing loss and maternal support on mother-infant interaction. Journal of Applied Developmental Psychology, 14, 407-426. http://dx.doi.org/10.1016/0193-3973(93)90017-P

Nunnally, J. C. (1978). Psychometry Theory (2nd ed.). New York: McGraw Hill Book Company.

Rosenberg, M. (1995). Global self-esteem and specific self-esteem: Different concepts, different outcomes. American Sociological Review, 60, 141-156. http://dx.doi.org/10.2307/2096350

Russell, K. C. \& Phillips-Miller, D. (2002). Perspectives on the wilderness therapy process and its relation to outcome. Child and Youth Care Forum, 31(6), 415-437. http://dx.doi.org/10.1023/A:1021110417119

Sandall, S., Smith, B., McLean, M. \& Ramsey, A. (2002). Qualitative research in early intervention/early childhood special education. Journal of Early Intervention, 25 (2) 129-136. http://dx.doi.org/10.1177/105381510202500210

Schilling, L. S. \& DeJesus, E. (1993). Developmental issues in deaf children. Journal of PediatricHealth Care, 7 , 161-166. http://dx.doi.org/10.1016/0891-5245(93)90039-K

Siavashi. (2009). Deaf education in Iran, problems and strategies. [Online] Available: www.idsf.ir

Tombull. H. R. (1990). Families, professionals, and exceptionality: A special partnership (2nd Ed.). New York: MacMillan.

Widerman, J.L. \& E. Widerman. (1995). Family systems-oriented school counseling. The School Counselor, 43: $66-3$.

Woolfe. (2001). Theory of mind in deaf children. Child development, 73, 768-778. 
Table 1. Correlation between components of mothers' attitude and deaf children's self-esteem

\begin{tabular}{lccc}
\hline \hline Components of mothers' attitude & $\mathbf{n}$ & $\mathbf{r}$ & $\mathbf{p}$ \\
\hline Attitude & 200 & $-0.20^{* *}$ & 0.006 \\
Mothers' positive attitude towards deafness & 200 & $0.22^{* *}$ & 0.002 \\
Mothers' negative attitude towards deafness & 200 & $-0.36^{* * *}$ & 0.000 \\
Mothers' attitude towards sign language & 200 & -0.10 & 0.15 \\
Mothers' attitude towards hearing-aid & 200 & $-0.20^{* *}$ & .005 \\
& & & 0.002 \\
Mothers' attitude towards toward the learning & 200 & $0.21^{* *}$ & \\
\hline \hline
\end{tabular}

$* * P<.01, * * * P<.001$

Table 2. Summary of the Interviews Results with Mothers

\begin{tabular}{|l|l|}
\hline Interviewee & What is your attitude towards your deaf children? \\
\hline Code 1 & $\begin{array}{l}\text { At first I was shocked but my husband's sympathy and visiting rehabilitation } \\
\text { centres helped me to accept my child's being deaf. I want to say that the people in } \\
\text { charge of the Exceptional Office should assign and allocate more classes of sign } \\
\text { language for deaf students and their parents. }\end{array}$ \\
\hline Code 2 & $\begin{array}{l}\text { I am upset because my son can't hear. The rehabilitative facilities are limited in } \\
\text { schools. The number of students is too much while the facilities are too few. I } \\
\text { believe if the media allocates more programmes to deaf people and families, this } \\
\text { would change the attitude of e society to deafness. }\end{array}$ \\
\hline Code 3 & $\begin{array}{l}\text { I have accepted the reality of deafness, but I feel that his deafness causes other } \\
\text { family members to be nervy. When we are watching TV programmes and my son } \\
\text { asks others to explain it to him, they become nervy because they don't have time } \\
\text { to do so. I wish deaf community centres would protect us and prepare } \\
\text { opportunities for more communication with society for them. }\end{array}$ \\
\hline Code 4 & $\begin{array}{l}\text { I couldn't believe it at first. But now that I see she has a great IQ like others and } \\
\text { she progresses I am really happy. I believe the officials of the Exceptional Office } \\
\text { should ask for parents'opinions too. They should also introduce successful } \\
\text { parents on TV and media to talk about their experiences. }\end{array}$ \\
\hline
\end{tabular}

